\title{
The global effects of Covid-19-induced uncertainty
}

\section{CAMA Working Paper 50/2020 May 2020}

\section{Giovanni Caggiano}

Monash University

University of Padova

Centre for Applied Macroeconomic Analysis, ANU

\section{Efrem Castelnuovo}

University of Melbourne

University of Padova

Centre for Applied Macroeconomic Analysis, ANU

\section{Richard Kima}

Monash University

\section{Abstract}

We estimate a three-variate VAR using proxies of global financial uncertainty, the global financial cycle, and world industrial production to simulate the effects of the jump in financial uncertainty observed in correspondence of the Covid-19 outbreak. We predict the cumulative loss in world output one year after the uncertainty shock due to Covid-19 to be about $14 \%$. 


\section{Keywords}

Covid-19, Financial Uncertainty, Vector AutoRegressions, Global financial cycle, World industrial production

\section{JEL Classification}

C32, E32

\section{Address for correspondence:}

(E) cama.admin@anu.edu.au

ISSN 2206-0332

The Centre for Applied Macroeconomic Analysis in the Crawford School of Public Policy has been established to build strong links between professional macroeconomists. It provides a forum for quality macroeconomic research and discussion of policy issues between academia, government and the private sector.

The Crawford School of Public Policy is the Australian National University's public policy school, serving and influencing Australia, Asia and the Pacific through advanced policy research, graduate and executive education, and policy impact. 


\title{
The global effects of Covid-19-induced uncertainty*
}

\author{
Giovanni Caggiano \\ Monash University \\ University of Padova \\ Centre for Applied Macroeconomic Analysis, ANU \\ Efrem Castelnuovo \\ University of Melbourne \\ University of Padova \\ Centre for Applied Macroeconomic Analysis, ANU \\ Richard Kima \\ Monash University
}

April 2020

\begin{abstract}
We estimate a three-variate VAR using proxies of global financial uncertainty, the global financial cycle, and world industrial production to simulate the effects of the jump in financial uncertainty observed in correspondence of the Covid-19 outbreak. We predict the cumulative loss in world output one year after the uncertainty shock due to Covid-19 to be about $14 \%$.

Keywords: Covid-19, Financial Uncertainty, Vector AutoRegressions, Global financial cycle, World industrial production.

JEL codes: C32, E32.
\end{abstract}

* We thank Giovanni Pellegrino for useful feedback. Corresponding author: Efrem Castelnuovo, Department of Economics, University of Melbourne, 111 Barry Street - FBE Building, Level 4, 3010 Melbourne - Victoria, Australia. Phone: +61 3834 42808, email: efrem.castelnuovo@unimelb.edu.au . 


\section{Introduction}

The Covid-19 outbreak has injected a huge amount of uncertainty in our lives. Worldleading immunologist Anthony Fauci (among many others) has written scientific articles on how to try "navigating the uncharted" from a medical and health standpoint, stressing how much we do not know yet on the coronavirus causing Covid-19 (see, e.g., Fauci, Lane, and Redfield (2020)). ${ }^{1}$ Unsurprisingly, a forward looking proxy like the VIX has immediately captured the extent of the Covid-19-induced uncertainty, as shown in Figure 1. As pointed out by Baker, Bloom, Davis, Kost, Sammon, and Viratyosin (2020), the peak value of financial volatility recorded in March 2020 is the highest in recent history, Great Recession included. This is bad news, because spikes in financial uncertainty have been associated to drops in real activity (see, among others, Bloom (2009), Caggiano, Castelnuovo, and Groshenny (2014), Leduc and Liu (2016), Basu and Bundick (2017), Caggiano, Castelnuovo, and Pellegrino (2017), Ludvigson, Ma, and Ng (2019), Caggiano, Castelnuovo, and Nodari (2019), and Cascaldi-Garcia and Galvão (2020)). Given the globality of the Covid-19-induced uncertainty shock, what does this imply for world output for the months to come?

This paper addresses this question by estimating a VAR featuring a proxy for global uncertainty (the VIX) and two state-of-the-art measures of global conditions, i.e., the global financial cycle index proposed by Miranda-Agrippino and Rey (2019), and the world industrial production index produced by Baumeister and Hamilton (2019). The use of the VIX as a proxy of global uncertainty has recently been validated by Caggiano and Castelnuovo (2019), who show that an estimated global uncertainty factor which carries information on the evolution of measures of financial volatility across 42 countries is highly correlated with the VIX. ${ }^{2}$ With respect to Caggiano and Castelnuovo's (2019) measure, the advantage of the VIX is that of being available in real time, something which enables us to quantify the effects of a recent shock such as the Covid-19 one. The global financial cycle index by Miranda-Agrippino and Rey (2019) - estimated with a principal component approach applied to 1,004 series of asset prices traded worldwide, a collection of corporate bond indices, and commodities prices - is included in the VAR to take into account the endogenous response of financial conditions to an uncertainty

\footnotetext{
${ }^{1}$ Dr. Fauci is the Director of the National Institute of Allergy and Infectious Diseases. His number of Google Scholar citations (as of April 30, 2020) is 207,527.

${ }^{2}$ The correlation between the VIX and the global financial uncertainty index by Caggiano and Castelnuovo (2019) is 0.87 (sample: July 1992-June 2019, which is the sample for which the global uncertainty measure by Caggiano and Castelnuovo (2019) is currently available). For a comprehensive survey of the literature on global uncertainty, see Castelnuovo (2019).
} 
shock, which might magnify the latter's direct effect on output (Alfaro, Bloom, and Lin (2018), Caggiano and Castelnuovo (2019)). Finally, the monthly world industrial production measure produced by Baumeister and Hamilton (2019), which refers to OECD countries plus six non-OECD players (Brazil, China, India, Indonesia, Russian Federation, South Africa) and covers 79\% of the IMF World Economic Outlook estimate of global GDP, enables us to: i) sharpen our identification of the causal effects going from uncertainty to output, an effort which would be more challenging when dealing with lower-frequency data (e.g., real GDP); ii) investigate the macroeconomic impact of the Covid-19-induced uncertainty shock at a global level.

Our main finding is the following. We predict a jump in uncertainty as large as the one occurred in March 2020 to induce a 14\% cumulative loss in world industrial production over one year, with a value as high as $22 \%$ falling within the $90 \%$ confidence interval. This finding offers clear support to the unprecedented policy interventions put in place by Governments and central banks in most countries to limit the recessionary effects of the Covid-19 shock. ${ }^{3}$

The paper is structured as follows. Section 2 offers a brief presentation of the data and the empirical framework. Section 3 reports the empirical results about the economic impact of the Covid-19 related uncertainty shock. Section 4 concludes.

\section{Data and empirical framework}

Data. We consider the three-variable system $\mathbf{X}_{t}=\left[V I X_{t}, G F C_{t}, 100 \log \left(W I P_{t}\right)\right]^{\prime}$, where VIX is our proxy for global financial uncertainty, GFC is the global financial cycle estimated by Miranda-Agrippino and Rey (2019), and WIP stands for the level of world industrial production computed by Baumeister and Hamilton (2019). The first two variables are modeled in levels, while WIP is modeled in logs and multiplied by 100 . The sample is January 1990-April 2019. The sample span is dictated by the availability of the VIX (as far as the beginning of the sample is concerned) and the GFC index (end of the sample). The sources of the data are: VIX - Federal Reserve Bank of St. Louis; GFC: Silvia Miranda-Agrippino's website ${ }^{4}$ WIP: Christiane Baumeister's website. ${ }^{5}$

VAR model. The reduced-form finite-order VAR representation reads:

\footnotetext{
${ }^{3}$ The April 2020 World Economic Outlook produced by the IMF offers an overview of these policy interventions. See https://www.imf.org/en/Publications/WEO/Issues/2020/04/14/weo-april-2020 .

${ }^{4} \mathrm{http}: / /$ silviamirandaagrippino.com .

${ }^{5}$ https://sites.google.com/site/cjsbaumeister/home .
} 


$$
\mathbf{X}_{t}=\sum_{j=1}^{p} \mathbf{A}_{j} \mathbf{X}_{t-j}+\boldsymbol{\eta}_{t}, \quad \boldsymbol{\eta}_{t} \sim \mathcal{N}(0, \boldsymbol{\Omega})
$$

where $\mathbf{A}_{j}$ are matrices of coefficients, and $\boldsymbol{\eta}_{t}$ is the vector of residuals whose variancecovariance is $\boldsymbol{\Omega}$. The VAR features equation-specific constants and linear trends. Our baseline model features $p=6$ lags. Identification is achieved by Cholesky-decomposing the variance-covariance matrix of the VAR residuals, $\Omega=\boldsymbol{P} \boldsymbol{P}^{\prime}$, where $\boldsymbol{P}$ is the unique lower-triangular Cholesky factor with non-negative diagonal elements. Following Leduc and Liu (2016), Caggiano, Castelnuovo, and Groshenny (2014), and Basu and Bundick (2017) (among others), we order the uncertainty proxy first in our VAR. This is done to allow uncertainty to have an immediate on-impact effect on financial conditions and real activity, effect that has actually materialized right after the arrival of the Covid-19 pandemic. This ordering is also consistent with the findings on exogeneity of financial uncertainty indicators recently put forth by Ludvigson, Ma, and Ng (2019) and Angelini, Bacchiocchi, Caggiano, and Fanelli (2019), and with the empirical evidence that points to financial uncertainty as a driver of the business cycle proposed by Baker, Bloom, and Terry (2020).

\section{Empirical evidence}

Calibration of the size of the COVID-19-induced uncertainty shock. To calibrate the size of the uncertainty shock due to the Covid-19 outbreak we look at the difference between the value of the VIX at its peak in mid March 2020 (on March 16, the VIX reached its record high level, jumping at 82.69) and its value exactly one month before, on February 16, 2020. The choice of the time span for computing the increase in the VIX is due to the monthly frequency of the data we model in this study. In mid-March 2020, the VIX stood at a level 5.6 times higher than in the previous month. How much of this increase can be attributed to the Covid-19 outbreak? Baker, Bloom, Davis, Kost, Sammon, and Viratyosin (2020) look at the measure of economic policy uncertainty (EPU) developed by Baker, Bloom, and Davis (2016) and calculate the proportion of newspapers articles that, in March 2020, mentioned Covid-19 along with the other keywords used to calculate the EPU index. They find that Covid-19 was mentioned in at least $90 \%$ of articles. We then attribute $90 \%$ of the observed jump in the VIX to the Covid-19 outbreak. ${ }^{6}$ This returns a scaling factor of $5.6 \times 0.9=5.04$,

\footnotetext{
${ }^{6}$ The underlying assumption here is that we can map information related to EPU to the VIX. The correlation between EPU and VIX in the January 1990-March 2020 sample is positive (0.46) and
} 
which is the one we apply to the uncertainty shock in our VAR exercise.

IRFs and cumulative loss. Figure 2 reports the impulse response functions of the VIX, GFC, and WIP to a 5-standard deviation uncertainty shock, along with the cumulative response of output. The response of the VIX is quite persistent, and it goes back to the pre-shock level one year after the shock. We believe the evolution of the VIX to be sensible, in light of the uncertainties that are likely to stay in place in the months following the Covid-19 shock (e.g., duration and characteristics of the lockdowns; effectiveness and availability of the medical tests; discovery, availability, and effectiveness of a vaccine; timing, size, features, and impact of the monetary and fiscal policy interventions; and so on). The reaction of global output is negative, persistent, and significant. The peak (negative) reaction, which takes place after four months, reads $-1.56 \%$. The negative response of output is consistent with the predictions of the real option theory in presence of non-convex adjustment costs, which implies that agents should optimally "wait-and-see", pause their investments in productive activities and purchases in durable goods, and wait until uncertainty is not there anymore. The response of GFC is also negative, persistent, and significant, with the deterioration of financial conditions predicted to be in place for 12 months. The negative response of global financial markets, joint with that of world output, is consistent with the finance-uncertainty multiplier hypothesis put forth by Alfaro, Bloom, and Lin (2018), who conjecture that financial stress due to uncertainty shocks might magnify the direct effects of uncertainty on output.

The bottom-right panel of Figure 2 plots the cumulative response of WIP over one year (period over which output's response is statistically significant). The cumulative output loss is estimated to be $-14 \%$. To put this figure into perspective, such a drop would be as large as the (unconditional, i.e., driven by all shocks) collapse of the yearly growth rate of WIP occurred in January 2009 (-14.1\%) in the midst of the Great Recession. The $90 \%$ confidence bands point to a relatively ample uncertainty surrounding our estimate, with values that range from $-6.17 \%$ to $-21.82 \%$. The impressive magnitude of the estimated world output loss echoes that on the US economy by Baker, Bloom, Davis, and Terry (2020), who estimate a year-on-year contraction in real GDP of nearly 11\% in 2020Q4 (half of which the authors attribute to the jump in financial uncertainty in March 2020), and by Ludvigson, Ma, and Ng (2020), who estimate a cumulative loss of $12.75 \%$ in US industrial production over a 10-month horizon.

Robustness. We consider alternative lag structures (3 and 12 lags) for our baseline significant. 
VAR; a bivariate VAR with VIX and WIP only; a VARX with US monetary policy shocks; and a VARX with the oil supply shocks. The latter two exercises are justified as follows. Miranda-Agrippino and Rey (2019) find US monetary policy shocks to be a driver of their GFC index (for a related analysis, see Miranda-Agrippino and Rey (2020)). Pellegrino $(2018,2020)$ shows that monetary policy shocks can induce fluctuations in uncertainty. ${ }^{7}$ Our baseline VAR does not feature US monetary policy shocks, an omission that calls for a check which also embeds estimates of such shocks. A similar justification is behind our exercise with the estimated series of oil supply shocks provided by Baumeister and Hamilton (2019). They show that oil supply shocks are important drivers of their measure of world industrial production. Again, our baseline VAR does not embed information on oil supply disturbances. The choice of treating these two shocks as exogenous variables in our robustness checks is due to their nature (i.e., they are meant to be exogenous). ${ }^{8}$ Figure 3 collects the responses of output estimated with the different specifications of the VAR framework we work with. Our checks confirms the solidity of the indications coming from our baseline exercise.

\section{Conclusions}

This paper estimates the response of world output to an uncertainty shock of size comparable to that attributed to the Covid-19 outbreak. We predict a cumulative fall of world industrial production over one year of about 14\%. Given that our analysis focuses on the world output effects of the Covid-19-induced uncertainty shock only, our estimate of the total loss due to the current pandemic is likely to be a conservative one.

\section{$5 \quad$ Funding}

Financial support from the Australian Research Council via the Discovery Grant DP160102281 and Discovery Grant DP190102802 is gratefully acknowledged.

\footnotetext{
${ }^{7}$ A somewhat related literature investigates the systematic US monetary policy response to variations in the VIX (Evans, Fisher, Gourio, and Krane (2015), Caggiano, Castelnuovo, and Nodari (2018)).

${ }^{8}$ The two VARX models consider contemporaneous and lagged values of the shocks (up to six lags, which is the dynamic structure selected for our baseline VAR). We thank Silvia Miranda-Agrippino for sending us the series of US monetary policy shocks estimated in Miranda-Agrippino and Rey (2019). The oil supply shocks series estimated by Baumeister and Hamilton (2019) is available at Christiane Baumeister's website: https://sites.google.com/site/cjsbaumeister/home .
} 


\section{References}

Alfaro, I., N. Bloom, and X. Lin (2018): "The Finance Uncertainty Multiplier," NBER Working Paper No 24571.

Angelini, G., E. Bacchiocchi, G. Caggiano, and L. Fanelli (2019): "Uncertainty Across Volatility Regimes," Journal of Applied Econometrics, 34(3), 437-455.

Baker, S., N. Bloom, and S. J. Davis (2016): "Measuring Economic Policy Uncertainty," Quarterly Journal of Economics, 131(4), 1539-1636.

Baker, S., N. Bloom, S. J. Davis, and S. J. Terry (2020): "COVID-Induced Economic Uncertainty," available at https://nbloom.people.stanford.edu/.

Baker, S., N. Bloom, And S. J. Terry (2020): "Does Uncertainty Reduce Growth? Using Disasters As Natural Experiments," available at https://nbloom.people.stanford.edu/research.

Baker, S. R., N. Bloom, S. J. Davis, K. Kost, M. Sammon, and T. Viratyosin (2020): "The Unprecedented Stock Market Reaction to COVID-19," available at https://nbloom.people.stanford.edu/research.

Basu, S., And B. Bundick (2017): "Uncertainty Shocks in a Model of Effective Demand," Econometrica, 85(3), 937-958.

Baumeister, C., And J. D. Hamilton (2019): "Structural Interpretation of Vector Autoregressions with Incomplete Identification: Revisiting the Role of Oil Supply and Demand Shocks," American Economic Review, 109(5), 1873-1910.

Bloom, N. (2009): "The Impact of Uncertainty Shocks," Econometrica, 77(3), 623685.

Caggiano, G., And E. Castelnudo (2019): "Global Uncertainty," Monash University and University of Melbourne, available at https://sites.google.com/site/efremcastelnuovo/.

Caggiano, G., E. Castelnuovo, and N. Groshenny (2014): "Uncertainty Shocks and Unemployment Dynamics: An Analysis of Post-WWII U.S. Recessions," Journal of Monetary Economics, 67, 78-92.

Caggiano, G., E. Castelnuovo, and G. Nodari (2018): "Risk ManagementDriven Policy Rate Gap," Economics Letters, 171, 235-238.

(2019): "Uncertainty and Monetary Policy in Good and Bad Times," available at https://sites.google.com/site/efremcastelnuovo/.

Caggiano, G., E. Castelnuovo, and G. Pellegrino (2017): "Estimating the Real Effects of Uncertainty Shocks at the Zero Lower Bound," European Economic Review, 100, 257-272.

Cascaldi-Garcia, D., And A. Galvão (2020): "News and uncertainty shocks," Journal of Money, Credit and Banking, forthcoming.

Castelnuovo, E. (2019): "Domestic and Global Uncertainty: A Brief Survey and Some New Results," CESifo Working Paper No. 7900. 
Evans, C., J. D. M. Fisher, F. Gourio, and S. Krane (2015): "Risk Management for Monetary Policy Near the Zero Lower Bound," Brookings Papers on Economic Activity, Spring, 141-196.

Fauci, A. S., H. C. Lane, and R. R. Redfield (2020): "Covid-19 - Navigating the Uncharted," New England Journal of Medicine, 382(13), 1268-1269.

Leduc, S., And Z. Liu (2016): "Uncertainty Shocks are Aggregate Demand Shocks," Journal of Monetary Economics, 82, 20-35.

Ludvigson, S. C., S. Ma, And S. NG (2019): "Uncertainty and Business Cycles: Exogenous Impulse or Endogenous Response?," American Economic Journal: Macroeconomics, forthcoming.

(2020): "COVID19 and The Macroeconomic Effects of Costly Disasters," available at https://www.sydneyludvigson.com/working-papers.

Miranda-Agrippino, S., And H. Rey (2019): "US Monetary Policy and the Global Financial Cycle," Bank of England and London Business School, mimeo.

Miranda-Agrippino, S., And H. Rey (2020): "The Global Financial Cycle after Lehman," American Economic Review Papers and Proceedings, forthcoming.

Pellegrino, G. (2018): "Uncertainty and the Real Effects of Monetary Policy Shocks in the Euro Area," Economics Letters, 162, 177-181.

US: A $\begin{aligned} & \text { (2020): "Uncertainty and } \\ & \text { Mourney into Non-Linear }\end{aligned}$ https://sites.google.com/site/giovannipellegrinopg/home. 


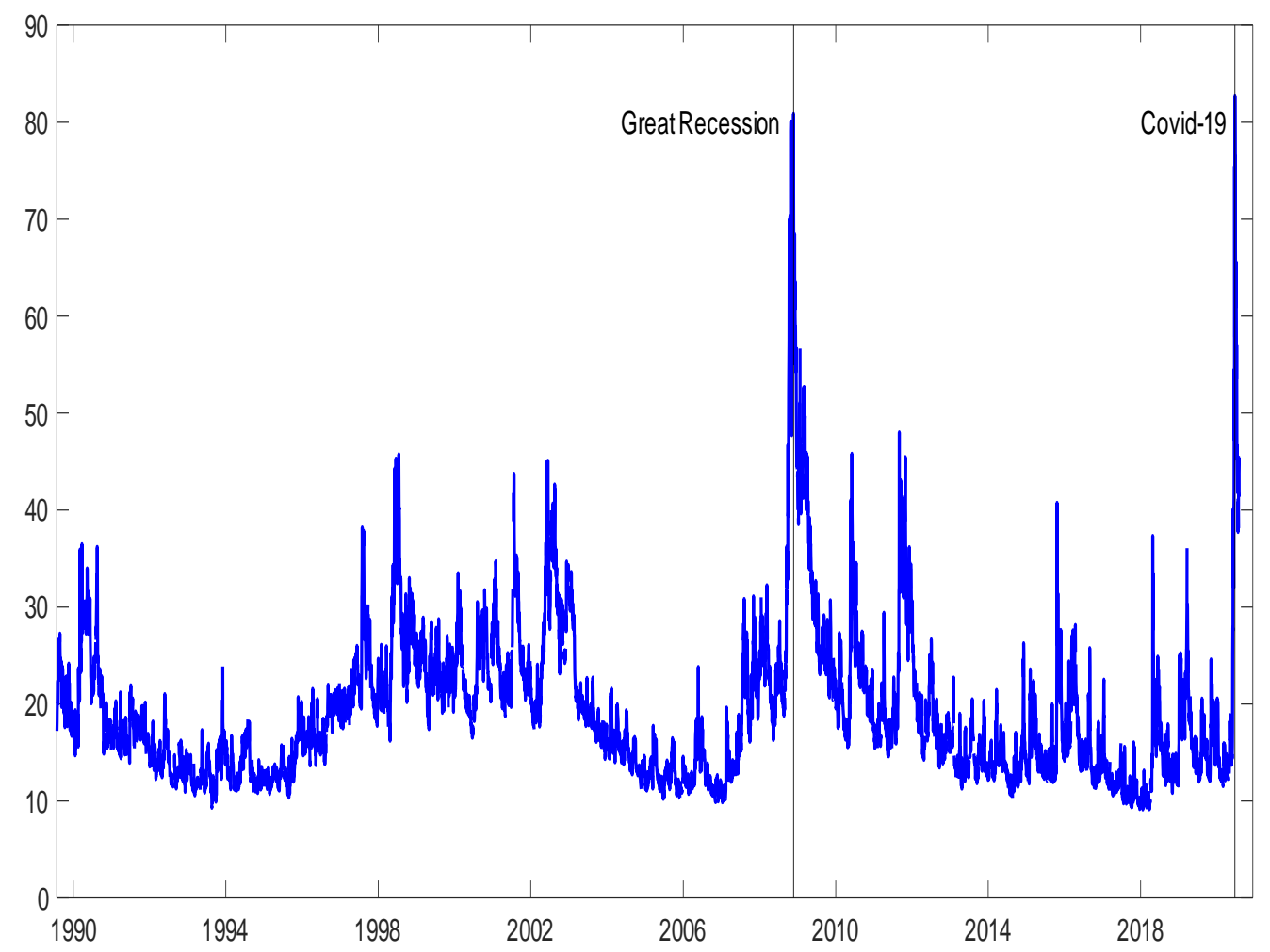

Figure 1: VIX. Evolution of the S\&P500 expected volatility (one-month horizon), daily data. 

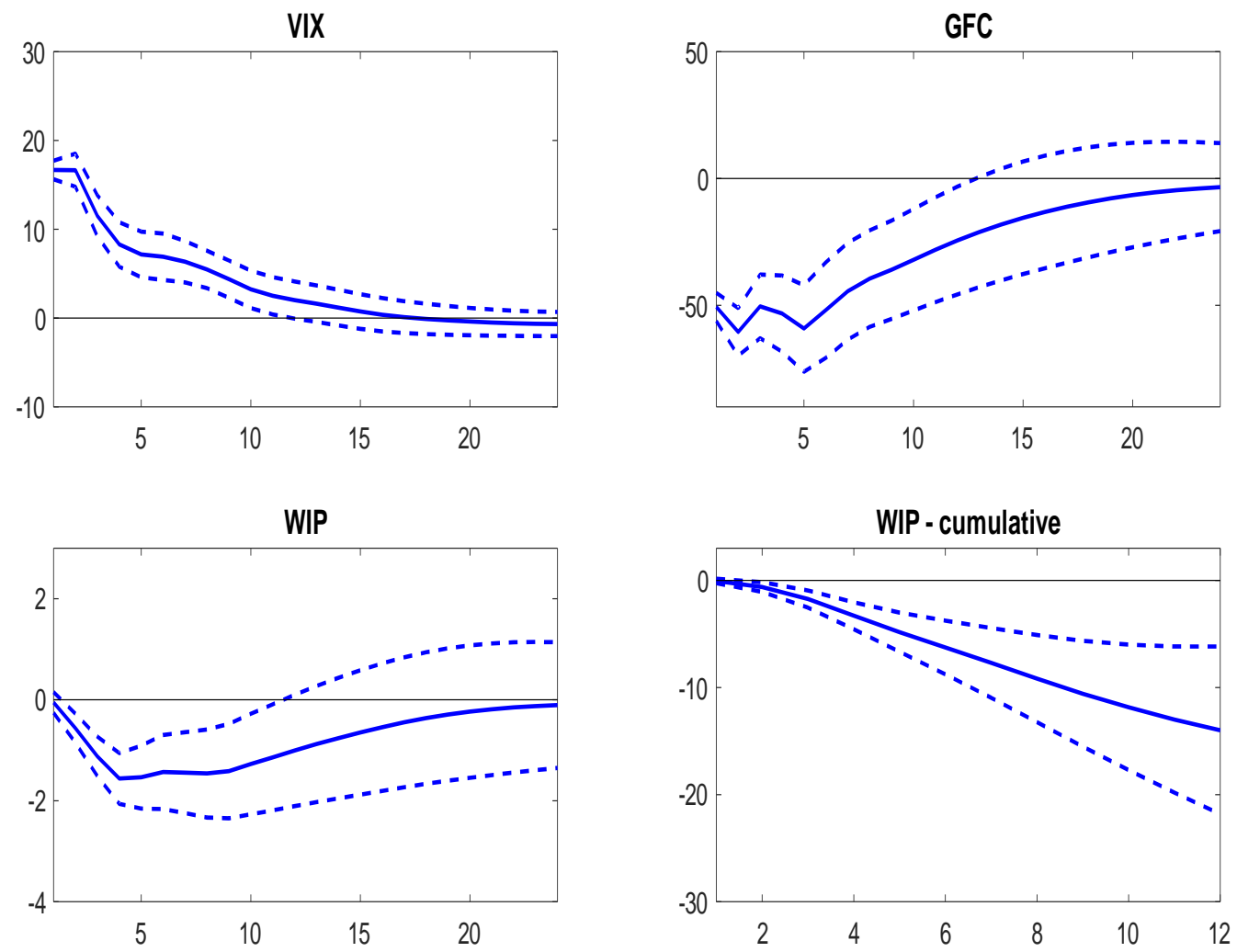

Figure 2: Impulse response functions to the Covid-19 uncertainty shock. Size of the shock: 5 standard deviations of a VIX shock estimated in normal times. Scaling factor computed by considering the jump of the VIX from mid-February to mid-March 2020. Solid line: Point estimates. Dashed lines: 90\% confidence interval. Panel $[2,2]$ reports the cumulative response of WIP over 12 months. 

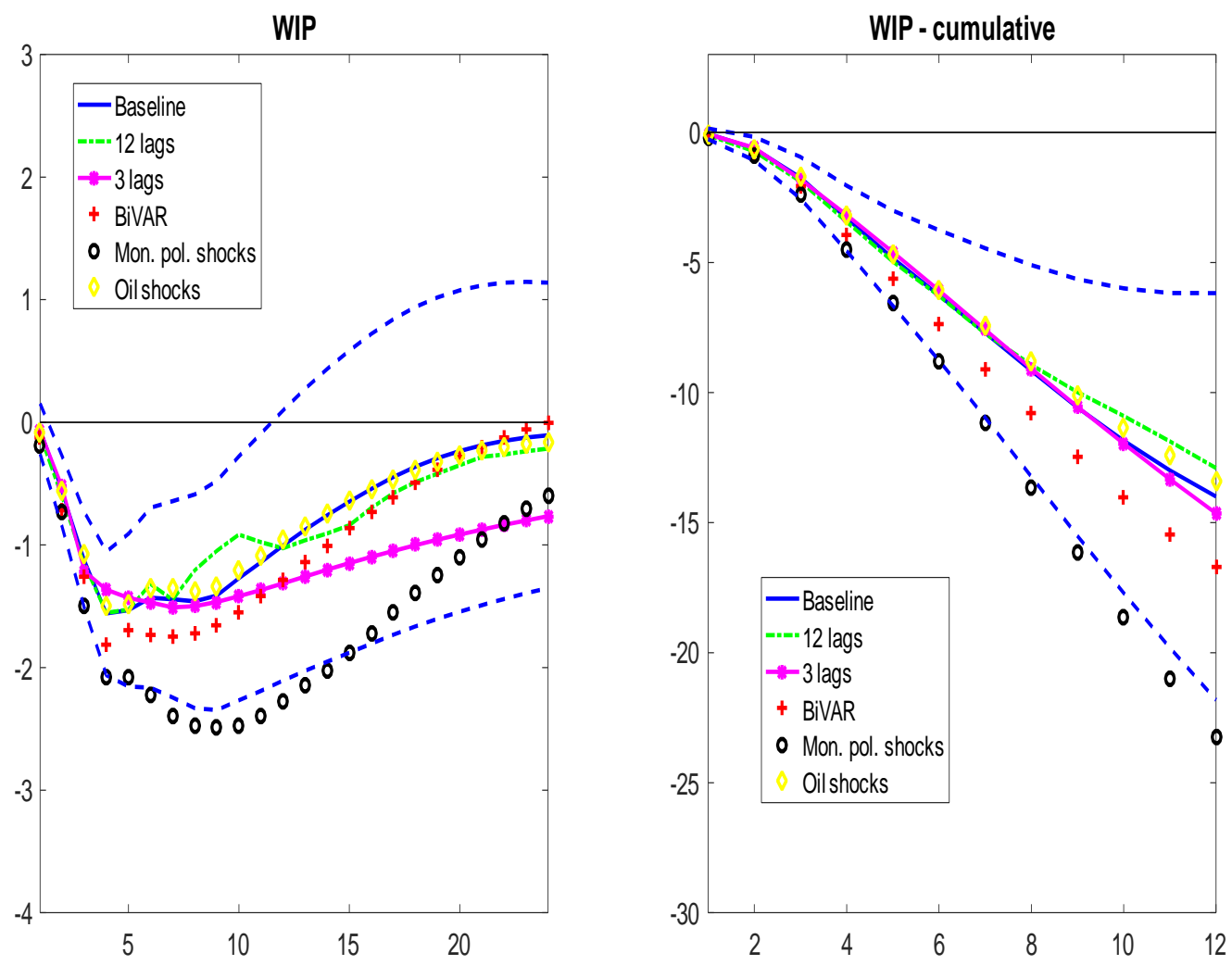

Figure 3: World output response to the Covid-19 uncertainty shock. Size of the shock: 5 standard deviations of a VIX shock estimated in normal times. Scaling factor computed by considering the jump of the VIX from mid-February to mid-March 2020. Solid line: Point estimates. Dashed lines: 90\% confidence interval related to our baseline VAR. Left panel: Level responses. Right panel: Cumulative responses over 12 months. Models other than the baseline: "12 lags" = trivariate model with 12 lags; "3 lags" = trivariate model with 3 lags; "BiVAR" = bivariate model with VIX and WIP only; "Mon. pol. shocks" = VARX with Miranda-Agrippino and Rey's (2019) US monetary policy shocks as exogenous variable; "Oil shocks" = VARX with Baumeister and Hamilton's (2019) oil supply shocks as exogenous variable. Sample of the analysis with monetary policy shocks: 1990M1-2010M2 due to the availability of the Miranda-Agrippino and Rey's (2019) series of shocks. 